\title{
Patients' falls in different sectors in a public-teaching hospital in Brazil
}

\begin{abstract}
Objective: Describe characteristics of adults and seniors falls in different sectors of a public teaching Hospital of Minas Gerais, Brazil.

Methods: Quantitative study, with a descriptive and retrospective approach, on reported falls of adults and seniors from different sectors of a teaching Public Hospital in Belo Horizonte, Minas Gerais (MG), Brazil such as the emergency room, medical wing and surgical wing. Data was collected through notifications and charts.

Result: Most falls occurred in men with ages between 55 and 62 years old. Presence of assistive devices, difficulty walking, altered emotional state, pain, and use of medications were found to be associated with high risk of falls. Bed falls at night were the most frequent. There are few nursing assessments that are relevant in preventing falls.

Conclusion: The greatest number of falls occurred in male patients during the night shift.The main comorbidities found were hypertension, diabetes mellitus, diseases of the circulatory system and diseases of the nervous system. The most common type of falls were in regards to falling from bed and falling from proper height. The identification of the risk of falling and the use of preventive measures reduce falls.
\end{abstract}

Volume 6 Issue 2 - 2021

\author{
Marilia Alves,' Kelen Adriane da Silva Souza, ${ }^{2}$ \\ Humberto Ferreira de Oliveira Quites, ${ }^{3}$ \\ Doane Martins da Silva, ${ }^{4}$ Palloma Fernandes \\ Estanislau Vaz Ventura ${ }^{5}$ \\ 'PhD in Nursing, Full Professor, Department of Applied Nursing, \\ School of Nursing at the Federal University of Minas Gerais, \\ Brazil \\ ${ }^{2}$ Master in nursing from the Postgraduate Program in Nursing at \\ the Federal University of Minas Gerais, Brazil \\ ${ }^{3} \mathrm{PhD}$ in Nursing, Adjunct Professor, Faculty of Nursing, Federal \\ University of São João Del Rei, Brazil \\ ${ }^{4} \mathrm{PhD}$ in Nursing, Department of Health Management, School of \\ Nursing, Federal University of Minas Gerais, Brazil \\ ${ }^{5} \mathrm{PhD}$ in Nursing, Substitute Professor, Department of Applied \\ Nursing, School of Nursing at the Federal University of Minas \\ Gerais, Brazil
}

Correspondence: Palloma Fernandes Estanislau Vaz Ventura. Escola de Enfermagem da Universidade Federal de Minas Gerais. Avenida Alfredo Balena, 190, sala 5I4, Bairro Santa Efigênia, Belo Horizonte, MG, Brasil, CEP: 30.130-100,

Email pallomavaz@hotmail.com

Received: April 01, 202I | Published: April 14, 202 I

\section{Introduction}

Health care quality and patient safety in health services have been an increasingly present concern worldwide, since the occurrence of adverse events has become frequent. According to the World Health Organization (WHO), one out of every ten people who need care will suffer an Adverse Event (AE) during hospital care, and 40\% to 50\% of these events are considered preventable. ${ }^{1}$ In Brazil the incidence of $\mathrm{AE}$ in patients was $7.6 \%$, and $66.7 \%$ of these events were considered preventable. $^{2}$

Patient falls in the hospital environment are among the A Emost commonly reported by health teams, being considered internationally and nationally a health problem. ${ }^{3}$ We understand as a fall all events in which the individual inadvertently falls to the ground or to another level lower than the starting position. ${ }^{4}$

Studies conducted in the United Kingdom have shown that the overall rate of falls in hospitalized patients is between 4.8 and 8.4 in 1,000 patients per day. ${ }^{5}$ In the United States, this rate ranges between 3 (three) and 5 (five) falls per 1,000 patients-day. ${ }^{6}$ In Brazil, a study ${ }^{7}$ showed that the incidence rate for falls was 1.98 per 1,000 hospitalized patients.

Falls suffered in hospital environment represent an important indicator related to lack of patient safety, revealing characteristics of care processes and of adequacy in relation to physical structures and resources necessary for prevention of AEin health care institutions. ${ }^{8} \mathrm{~A}$ patient who falls, in addition to worsening of the initial state of health, is subject to situations such as increased number of hospitalization days and deteriorated condition due to trauma, lacerations and abrasions, among others factors. ${ }^{9}$

In this context, with the purpose of improving the quality of care, hospital institutions must establish mechanisms and strategies for patient safety. Thus, it is relevant to know more about the occurrence of falls in sectors still little explored, such as the emergency room and the surgical wing, which may contribute to the planning of preventive interventions and promotion of patient safety. Therefore, as part of a large project on patient safety, this study aimed to describe characteristics of adults and seniors falls in different units of a public teaching Hospital.

\section{Method}

Quantitative study, with a descriptive and retrospective approach, on reported falls of adults and seniors in different units of a teaching public hospital in Belo Horizonte, Minas Gerais (MG), Brazil. The Hospital provides services to patients of clinical and surgical emergency, traumatologic and nontraumatologic, in different units and has an installed capacity of 300 beds. The study population was of 217 reports of falls involving adult and senior individuals, registered electronically by the Center of Quality Management, from March 2010 to December 2012. Initially, 264 fall notifications were identified, out of which 47 were excluded due to insufficient records, 
caused by initial filling. The sectors of study were Emergency Room, Medical Wing and Surgical Wing. In addition to notifications, the study employed data from patient records made available by the information technology sector. The variables were: sex, age group, amount of time that the patient was hospitalized until the occurrence of fall, initial diagnosis during admission, patient's mental state, comorbidities, risk factors associated to falls, use of medication that are a known risk for falls, location and time of occurrence, consequences and prior nursing evaluation that identified risk of fall.

Data related to falls records were handled by descriptive statistics, through distribution of frequencies, means and standard deviation. Tabulation was performed using the program Statistic Package for Social Sciences (SPSS) 19.0 for Windows. We calculated the incidence of falls per sector by using the formula proposed by the Manual of Nursing Indicators of the Hospital Quality Commitment Program. ${ }^{10}$
Ethical aspects complied with Resolution No. 466/12, of the National Health Council. ${ }^{11}$ The project was approved by the Research Ethics Committee of the Federal University of Minas Gerais (COEP/ UFMG), CAAE number: 15649213.7.0000.5149.

\section{Results}

Over the period of the study, there was an alternation concerning the number of notifications related to falls, with increase from the first to the second year of the study and considerable drop later in the following year $(n=68)$. Incidence relating to falls also presented the same trend, as shown in Figure 1.

Fall notifications that were distributed according to the units under study showed that the emergency room $(\mathrm{n}=101)$ and the surgical wing $(\mathrm{n}=85)$ were the units that had the most notifications (Table 1$)$.

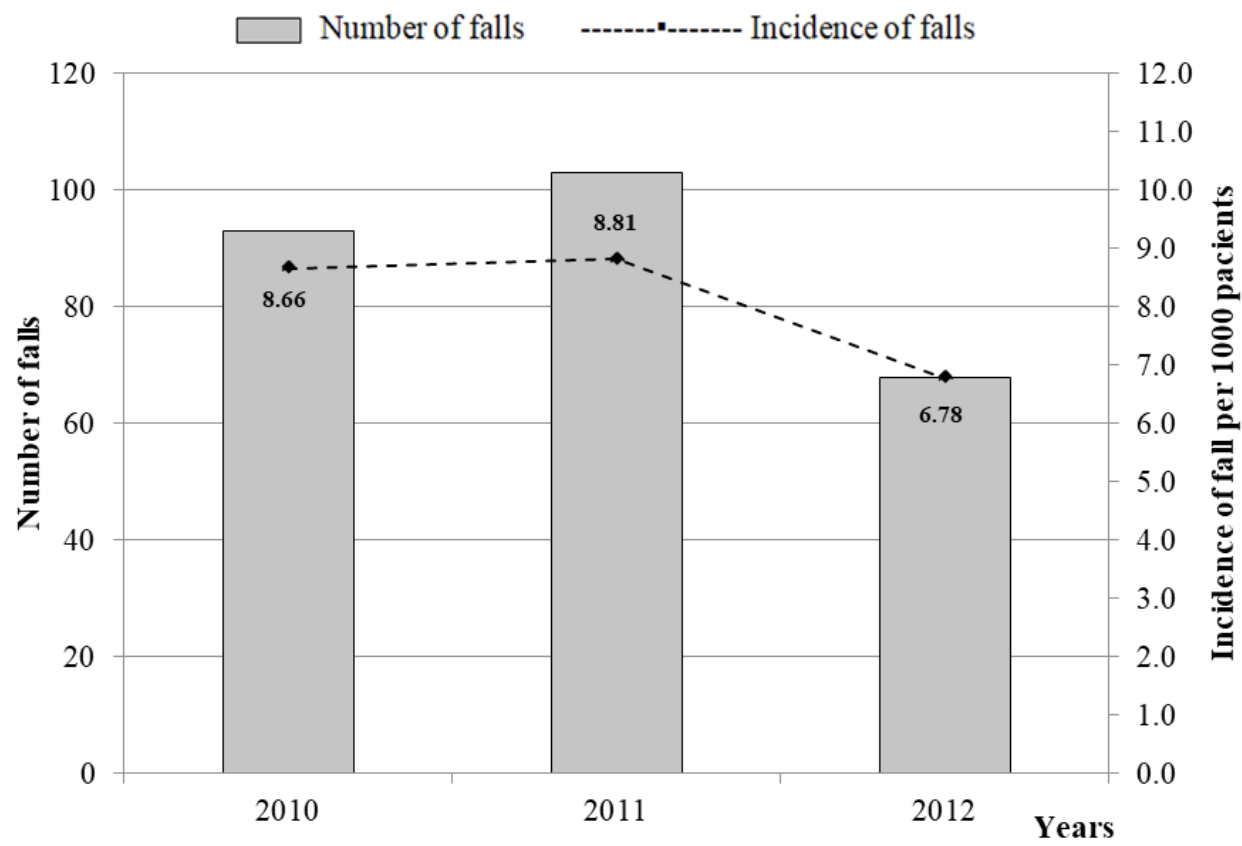

Figure I Distribution of notifications and incidence of falls in a large publicteaching Hospital from 2010 to 20I2, in Belo Horizonte, MG, Brazil.

Table I Characterization of patients who suffered intrahospital falls from 2010 to 2012 . Arranged by units, according to sex, age group, time of hospitalization until fall, diagnosis and mental state in a large publicteaching hospital in Belo Horizonte, MG, Brazil. $(n=2 / 7)$

\begin{tabular}{llll}
\hline Variables & Emergency room & Surgical wing & Medical wing \\
\hline Sex & $\mathbf{N}=101(\%)$ & $\mathbf{N}=85(\%)$ & $\mathbf{N}=3$ I (\%) \\
Male & $74(73.2)$ & $66(77.7)$ & $26(83.9)$ \\
Female & $27(26.7)$ & $19(22.3)$ & $5(16.1)$ \\
Mean age & $57.4( \pm 17.0)$ & $55,6( \pm 18,6)$ & $61.7( \pm 13.5)$ \\
Age group & & & \\
19 to 39 years & $13(12.9)$ & $18(21.2)$ & $1(3,2)$ \\
40 to 59 years & $41(40.6)$ & $34(40.0)$ & $12(38.7)$ \\
60 years or older & $47(46.5)$ & $33(38.9)$ & $18(58.1)$ \\
\hline
\end{tabular}




\begin{tabular}{|c|c|c|c|}
\hline Variables & Emergency room & Surgical wing & Medical wing \\
\hline & $N=10 \mid(\%)$ & $\mathbf{N}=85(\%)$ & $\mathbf{N}=31$ (\%) \\
\hline Hospitalization time until fall (days) & $2.6( \pm 4.8)$ & $10.1( \pm 9.5)$ & $21.0( \pm 22.5)$ \\
\hline \multicolumn{4}{|l|}{ Admission diagnosis } \\
\hline $\begin{array}{l}\text { Endocrine, nutritional and } \\
\text { metabolic disorders }\end{array}$ & $6(5.9)$ & $8(9.4)$ & $2(6.45)$ \\
\hline Mental and behavioural disorders & $3(3.0)$ & $\mathrm{I}(\mathrm{l} .2)$ & I $(3,2)$ \\
\hline Nervous system diseases & $21(20.8)$ & $\mathrm{I}(\mathrm{I} .2)$ & $5(16.1)$ \\
\hline Circulatory system diseases & $18(17.8)$ & $22(25.9)$ & $6(19.3)$ \\
\hline Respiratory system diseases & $8(7.9)$ & $0(0.0)$ & $3(9.7)$ \\
\hline Digestive system diseases & $8(7.9)$ & $\mathrm{I}(\mathrm{l} .2)$ & $6(19.3)$ \\
\hline Musculoskeletal system diseases & $0(0.0)$ & $4(4.7)$ & $0(0.0)$ \\
\hline Genitourinary system diseases & $0(0.0)$ & $0(0.0)$ & $2(6.5)$ \\
\hline External causes & $27(26.7)$ & $4 \mathrm{I}(48.2)$ & $6(19.3)$ \\
\hline Pregnancy, childbirth, puerperium & $0(0.0)$ & $\mathrm{I}(\mathrm{l} .2)$ & $0(0.0)$ \\
\hline Unspecified & $7(6.9)$ & $5(5.9)$ & $0(0.0)$ \\
\hline \multicolumn{4}{|l|}{ Mental state } \\
\hline Orientation & $56(55.4)$ & $60(70.6)$ & $10(32.3)$ \\
\hline Mental confusion & $39(38.6)$ & $24(28.2)$ & $21(67.7)$ \\
\hline Depression of sensorium & $2(2.0)$ & $0(0.0)$ & $0(0.0)$ \\
\hline Unreported & $4(4.0)$ & I (I.2) & $0(0.0)$ \\
\hline
\end{tabular}

The highest number of falls, considering different units, occurred in male patients with agevarying between 55 and 62 years. The emergency room was the sector with the highest number of notifications in the male age group of 40 to 59 years $(40.6 \%)$ and seniors (46.5\%). The medical wing was the sector in which the elapsed time between admission and registration of event was the longest, with an average of 21 days.

Considering the comorbidities identified, hypertension (44.2\%) and Diabetes Mellitus (22.6\%) were the top two comorbidities found. Diseases of the circulatory system were frequent diagnoses in patients in the surgical wing $(25.9 \%)$ and medical wing $(19.3 \%)$. In the emergency room, diseases related to the nervous system also represented a considerable percentage $(20.8 \%)$. It is also noteworthy the high number of falls $(67.7 \%)$ in the medical wing in regards to patients with mental confusion. Falls in the surgical wing (70.6\%) and emergency room (55.4\%), occurred mostly in patients who were oriented in regards to time and space.

There were other important risk factors for the occurrence of falls found. For patients who received care in the emergency room, we identified the use of devices such as probes, collectors and others (92.8\%), absence of companion (35.7\%), presence of psychomotor agitation $(26.5 \%)$, and abnormal gait (25.5\%). For the surgical wing, in addition to the use of these devices (96.5\%) and abnormal gait $(58.9 \%)$, we emphasize the presence of emotional alteration $(50.6 \%)$ and report of pain (45.9\%). In the medical wing, the highest percentages of falls were observed in patients who used the devices mentioned above (96\%), presented emotional alterations $(64.5 \%)$, and had no companion $(51.6 \%)$.

Most patients (89\%) who suffered falls were under the use of medication with an increased risk of fall, in the emergency room $(81.8 \%)$, surgical wing $(95.3 \%)$, and medical wing $(93.9 \%)$. The mean use of medication with increased risk for fall was $3.9( \pm 2.53)$ per patient, ranging from 1 to 12 medications. Among the most commonly used medications, we point out painkillers in the surgical wing $(61.2 \%)$, antihypertensives in both the medical wing $(64.5 \%)$ and the surgical wing (45.9\%), antiepileptic in the surgical wing $(48.2 \%)$ and the medical wing $(48.3 \%)$ and anticoagulant/antithrombotic in both the surgical wing $(60.0 \%)$ and the medical wing $(64.5 \%)$.

Patientsthatfall from their own bed and in the environment where they are being treated were the two situations that reached the highest percentages in all three units in this study (Table 2). We can also highlight, based on the notifications from the surgical wing, patients that fall from their own height $(31.8 \%)$, that fall in the bathroom $(18.8 \%)$, or on the way to the bathroom $(15.3 \%)$ as situations present on a daily basis. 
Table 2 Distribution of intrahospital falls from 2010 to 2012, by units, according to type, location of fall andtime of occurrence in a large publicteaching hospital in Belo Horizonte, MG, Brazil $(n=217)$

\begin{tabular}{|c|c|c|c|}
\hline Variables & Emergency room & Surgical wing & Medical wing \\
\hline & $N=101(\%)$ & $\mathrm{N}=85$ (\%) & $\mathbf{N}=3 \mathbf{I}(\%)$ \\
\hline \multicolumn{4}{|l|}{ Type of fall } \\
\hline Bed & $87(86.1)$ & $43(50.6)$ & $23(74.1)$ \\
\hline Own height & $9(8.9)$ & $27(3 \mid .8)$ & $6(19.4)$ \\
\hline Chair & $3(3.0)$ & $14(16.5)$ & $0(0.0)$ \\
\hline Other & $2(2.0)$ & $0(0.0)$ & $0(0.0)$ \\
\hline Unreported & $0(0.0)$ & $\mathrm{I}(1.2)$ & I (3.2) \\
\hline \multicolumn{4}{|l|}{ Fall location } \\
\hline Sector of origin & $84(83.2)$ & $46(54.1)$ & $22(7 \mid .0)$ \\
\hline Bathroom & $5(5.0)$ & $16(18.8)$ & $3(9.7)$ \\
\hline Way to bathroom & $4(4.0)$ & $13(\mid 5.3)$ & $4(12.9)$ \\
\hline Corridor & $2(2.0)$ & $2(2.4)$ & $\mathrm{I}(3.2)$ \\
\hline Other & I (I.0) & $0(0.0)$ & $0(0.0)$ \\
\hline Unreported & $5(5.0)$ & $8(9.4)$ & $\mathrm{I}(3.2)$ \\
\hline \multicolumn{4}{|c|}{ Time of occurrence } \\
\hline Day & $4 I(40.6)$ & $29(34.1)$ & $9(29.0)$ \\
\hline Night & $60(59.4)$ & $56(65.9)$ & $22(7 \mid .0)$ \\
\hline
\end{tabular}

Another factor identified through the notifications was the time of occurrence and it was observed that, in all three units, most falls occurred at night. For the medical wing, the percentage of registrations was $71.0 \%$, followed by the surgical unit with $65.9 \%$ and then the emergency room with $59.4 \%$. Considering the falls occurred during the day shift, the highest frequency o falls was observed in the morning $(18.9 \%)$. Three notifications of falls $(1.4 \%)$ that occurred in the day shift were not specific if the occurrence was in the morning or afternoon.

Part ( $\mathrm{n}=78$ ) of all falls caused some type of deleterious consequence to patients. When distributed by unit, it was determined that patients of the surgical floor $(36.6 \%)$ and medical wing $(33.3 \%)$ required care as a result of a fall in approximately one third of the registered cases. A high number of events registered in the emergency room (47.1\%) also had a deleterious consequence. These values concern 191 notifications due to the lack of registration in $11.9 \%$ of the total of notifications. Considering the consequences suffered by patients after the falls, we point out the presence of cut-contusion wounds in $37.2 \%$ of cases ( $n=29)$, presence of mild trauma, swelling and bruising in $44.9 \%(n=35)$ and presence of pain caused by the fall in affected body part in $16.7 \%(n=13)$. The emergency room was the sector with the highest percentage $(52.6 \%)$ of consequences from fall, followed by the surgical wing $(35.8 \%)$.

Included in this context, seniors constitute a high-risk group that deserve special attention. Considering the number of total events reported during the period of the study, $45.4 \%(n=98)$ referred to this age group. We point out among the risk factors in the different units: presence of emotional alteration of $47.4 \%$ in the medical wing, presence of pain in the surgical wing in $45.5 \%$ of registrations, and $93.5 \%$ of patients use antihypertensive medication in the emergency room, $97.0 \%$ on the surgical wing and $94.7 \%$ on the medical wing.
In this group, $67.4 \%$ if patients who were oriented still fell in the emergency room and $66,7 \%$ in the surgical wing, while $63.2 \%$ of patients in a state of mental confusion fell in the medical wing. More than half of the falls were from thesenior's own bed in the emergency room $(87.0 \%)$, surgical wing $(54.5 \%)$ and medical wing $(68.4 \%)$. It is also noteworthy that, considering the falls in this groupfrom their own bed, most patients were on gurneys.

Out of all patients who suffered a fall and generated anotification addressed in this study, only 79 had been subjected to prior evaluation of risk by the nursing staff in their respective units. Another important observation is that a little less than half $(41.9 \%, n=91)$ of the total number of registrations contained some type of measure or proposed a preventive conduct to avoid the occurrence of falls in the units in this study. Considering the practices identified in the notifications, the most prevalent were maintaining the bed rails elevated (40.6\%), providing instructions to patient and companion on the risk of fall in the unit $(33.3 \%)$, providing information on the need to have a full-time companion with the patients who are at risk (26.4\%), and performing physical containment and or constraint in patients according to the indication (17.6\%).

\section{Discussion}

The results show that there was an increase in the reporting of falls from the first to the second year, followed by a sharp decline in the number and incidence of falls in the period of the study. Such situation may be explained by the initial improvement of notification in the beginning of the process, which subsequently suffered losses in regards to investments, on resources and personnel, consequently impacting its continuity. This inference is based on aspects identified in a recent study in Brazil, in which main factors for the decrease of registrations were the limitation of time and human resources, fear 
of penalty, difficulty of people to report their own errors, lack of awareness about the importance of reporting events, lack of changes and lack of responses from managers after reporting. ${ }^{3}$

In general, when analyzing these data, no major differences were observed as for the fallsin the units assessed. Specifically, work routines and processes contributed in a particular manner to the occurrence of the AE. In the surgical wing and medical wing, we identified the following as important factors for the occurrence of falls: the chronification of a patient's disease, the number of care devices, difficulties involving mobility, prolongation of hospitalization, and constant use of medication. It should also be emphasized that, in addition to the aforementioned factors, these sectors present difficulties related to management of human resources, routines and situations that might hinder the implementation of measures addressing the prior assessment of risk of fall as well as the inclusion of prevention strategies.

The characteristics of the intrahospital falls presented in this study corroborate other studies on the subject. Male patients presented higher incidence of fall, ${ }^{12,13}$ which may be connected with difficulty, often cultural, of men to request or accept assistance to perform common activities in the hospital environment, as getting up from the bed. ${ }^{12}$

The higher incidence of falls in older age groups was also observed in other studies. ${ }^{13,14}$ Characteristics such as impaired physical mobility, postural instability, decreased functional, cognitive and visual capacity and the considered physiological changes related to the aging process, are important predictors for identifying such event. ${ }^{15}$

Medical diagnoses related to diseases of the digestive system diseases, of the circulatory system diseases, of the respiratory system, neoplasm, hypertension and vascular disease were present in the falls risk, as observed in studies. ${ }^{16,17}$ The acute and chronic condition of a disease can bring mental and physical changes that, associated with the increasing consumption of medicines, increase the risk of a patient falling. ${ }^{18,19}$ As for the mental state of patients who suffered a fall in the different unit, it was possible to identify that low orientation and mental confusion suggest increased fall risk.

Studies show that the use of devices such as tubes and catheters for intravenous medication or for monitoring, the presence of acute disease or recent surgical procedures, the need for bed rest for recovery, abnormalities involving walking, the need for assistance as the use of a cane or walker and need to use a wheelchair constitute a challenge for fall prevention. ${ }^{20,21}$

Another important situation that may favor this AE in hospitalized patients is having a patient remain alone during the period of hospitalization, which may increase risk of fall due to the difficulty of individual assistance by professionals and the lack of assistance from companions to perform basic activities, endangering the patient. ${ }^{13}$

Several drugs may increase fall risk, specially medication for cardiovascular diseases (such as an anti-arrhythmic and diuretics), ${ }^{12}$ benzodiazepines, antidepressants, antipsychotics, antiepileptic, antiparkinson medication, opiates and anti-anxiety drugs. ${ }^{22,23}$ The use of antihypertensive medications may cause postural hypotension, causing the patient to fall. The use of painkiller in great quantity in the surgical wing often with a sedative effect in the post-op period also predisposes the patient to the risk of falling. ${ }^{22}$

Falls from their own bed was the main type of fall registered in the units in this study, similarly to another study. ${ }^{7}$ It is important to note that beds of theseunits are often not suitable for long periods of hospitalization. In the surgical wing, most patients remain on narrow and high gurneys, which reduces the patient's mobility and may increase risk of fall, thus endangering the patient. ${ }^{24}$

As for the location of occurrence of falls, studies ${ }^{9,14}$ showed that most of these events occurred in the patient's room or in the unit where the patient is, thus corroborating this study. Similarly, studies also showed that the highest frequency of falls occurred during the night. ${ }^{9,12}$ During the night, normally, there is reduced number of professionals working, which decreases the monitoring and the bed visits, in addition to the silent and dark environment that enhances fall risk. ${ }^{12,14}$

Assessing patients to know the risks that may lead to the occurrence of falls is a task that must be carried out by the whole staff, but mainly by the nurse, who is responsible for managing the care provided to patients and of ensuring a safe and damage-free care. The nursing staff, being responsible for direct health care, remains longer with the patient, which enables prior identification of fall risk.

A study found that patients who suffered falls had low percentage of nursing diagnosis for fall risk, which could mean low attention to such risk. ${ }^{12}$ Identifying patients who have a high risk of falling and then applying preventive measures enable the reduction of falls ${ }^{13}$, in addition to providing satisfactory health care quality and reducing morbidity, as well as reducing possible unnecessary costs.

Nursing has a relevant role in patient safety. The staff must intervene in the modifiable risk factors and invest in permanent education for professionals. Health education geared towards patients and companions is essential to enhance the prevention of falls and their consequences. In addition, there should be continuous monitoring and evaluation of indicators aimed at preventing this adverse event.

\section{Conclusion}

The occurrence of falls was more frequent in males, in senior patients, and at night, from the own bed and in the unit where treatment is being conducted. As predisposing factors, we found the use of assistive devices, mobility difficulties, prolongation of hospitalization, constant use of medications, lack of bed rails, and use of high gurneys to accommodate patients in the emergency room.

Report of AE should be perceived by health professionals as an aid for planning prevention actions and not just as a routine focused on registry. Identifying risk factors for falls is important, but not sufficient for safe, quality care practices. Managing processes demands interest, organization and dedication from the agents involved.

Managerial support and investment in resources are key to the success of strategies and development of an organizational culture of patient safety, considering that it is a modifiable event. Studies addressing patients and relatives, particularities of different units, their dynamics and possible risk factors are suggested. This study has the limitation of lacking generalizability, since it was conducted in a single hospital.

\section{Acknowledgments}

National Council for Scientific and Technological Development (CNPq).

\section{Conflicts of interest}

The authors declare no conflict of interest.

\section{References}

1. World Health Organization (WHO). World alliance for patient safety: programme. Geneva: WHO; 2004 
2. Mendes W, Martins M, Rozenfeld S. The assessment of adverse events in hospitals in Brazil. Int J Qual Health Care. 2009;21(4):279-284.

3. Lorenzini E, Santi JAR, Báo ACP. Segurança do paciente: análise dos incidentes notificados em um hospital do sul do Brasil. Rev Gaucha Enferm. 2014;35(2):121-127.

4. World Health Organization (WHO). Who global report on falls preventions in older age. WHO; 2007.

5. World Health Organization (WHO). Summary of the evidence on patient safety: implications for research. WHO; 2008.

6. Oliver D, Healey F, Haines TP. Preventing falls and fall-related injuries in hospitals. Clin Geriatr Med.2010;26(4):645-692.

7. Paiva MCMS, Paiva SAR, Berti HW, et al. Caracterização das quedas de pacientes segundo notificação em boletins de eventos adversos. Rev Esc Enferm USP.2010;44(1):134-138.

8. Prates CG, Luzia MF, Ortolan MR, et al. Quedas em adultos hospitalizados: incidência e características desses eventos. CiêncCuid Saúde. 2014;13(1):74-81.

9. Correa AD, Marques IAB, Martinez MC, et al. Implantação de um protocolo para gerenciamento de quedas em hospital: resultados de quatro anos de seguimento. Rev Esc Enferm.2012;46(1):67-74.

10. Programa de qualidade hospitalar (CQG). Manual de indicadores de enfermagem do Núcleo de Apoio a Gestão Hospitalar (NAGEH). São Paulo: Associação Paulista de Medicina/ Conselho Regional de Medicina do Estado de São Paulo; 2006.

11. Ministério da Saúde (BR). Conselho Nacional de Saúde. Resolução No 466, de 12 de dezembro de 2012.।

12. Costa SGRF, Monteiro DR, Hemesath MP, et al. Caracterização das quedas do leito sofridas por pacientes internados em um hospital universitário. Rev Gaúcha Enferm.2011;32(4):676-681.

13. López VME. Prevalencia de caídas en pacientes hospitalizados en dos instituciones de salud de Pereira. Cultura del Cuidado. 2010;7(1):16-23.
14. Abreu C, Mendes A, Monteiro J, et al. Falls in hospital settings: a longitudinal study. Rev Latino-Am Enferm. 2012;20(3):597-603.

15. Shuto H, Imakyure O, Matsumoto J, et al. Medication use as a risk factor for inpatient falls in an acute care hospital: a case-crossover study. $\mathrm{Br} J$ Clin Pharmacol. 2010; 69(5):535-42.

16. Schwendimann R, Buhler H, De Geest S, et al. Characteristics of hospital inpatient falls across clinical departments. Gerontol. 2008;54(6):342-348.

17. Vitor AF, Lopes MVO, Araújo TL. Diagnóstico de enfermagem risco de quedas em pacientes com angina instável. Rev Rene. 2010;11(1):105-113.

18. Melo França MJD, Mangueira SO, et al. Diagnósticos de enfermagem de pacientes com necessidade de locomoção afetada internados em uma unidade hospitalar. Rev Eletrônica Enferm. 2013;15(4):878-885.

19. Ferreira MC, Tozatti J, Fachin SM, et al. Redução da mobilidade funcional e da capacidade cognitiva no diabetes melito tipo 2. Arq Bras Endocrinol Metabol. 2014;58(9): 946-952.

20. Walsh W, Hill KD, BennelK, et al. Local adaptation and evaluation of a falls risk prevention approach in acute hospitals. Int J Qual Health Care. 2011;134-141.

21. Urbanetto JS, Creutzberg M, Franz F, et al. Morse fallscale: tradução e adaptação transcultural para a língua portuguesa. Rev Esc Enferm USP. 2013;47(3):569-575.

22. Huang AR, Mallet L, Rochefort CM, et al. Medication-related falls in the elderly: causative factors and preventive strategies. Drugs Aging. 2012;29(5):359-376.

23. Tanaka M, Suemaru K, Ikegawa Y, et al. Relationship between the risk of falling and drugs in an academic hospital. Yakugaku Zasshi. 2008;128(9):1355-1361.

24. Álvares LM, Lima RC, Silva RA. Ocorrência de quedas em idosos residentes em instituições de longa permanência em Pelotas. Cad Saúde Pública. 2010; 26(1):31-40. 